Journal of Applied Pharmaceutical Science Vol. 6 (06), pp. 001-007, June, 2016

Available online at http://www.japsonline.com

DOI: $10.7324 / J A P S .2016 .60601$

ISSN 2231-3354 (cc)) BY-NC-SA

\title{
Combination of resveratrol and fluoxetine in an acute model of depression in mice: Prevention of oxidative DNA fragmentation and monoamines degradation
}

\author{
Omar A.H. Ahmed-Farid ${ }^{1}$, Rania F. Ahmed ${ }^{2 *}$, Dalia O. Saleh ${ }^{2}$ \\ ${ }^{1}$ Department of Physiology, National Organization for Drug Control and Research, Giza, Egypt. \\ ${ }^{2}$ Department of Pharmacology, National Research Centre,(ID: 60014618), Dokki, 12622, Giza, Egypt.
}

\section{ARTICLE INFO \\ Article history: \\ Received on: 05/05/2016 \\ Revised on: 30/05/2016 \\ Accepted on: 11/06/2016 \\ Available online: 28/06/2016}

Key words:

Depression; Fluoxetine;

Monoamines; Oxidative

stress; Resveratrol.

\begin{abstract}
Resveratrol (RSV) is a natural polyphenol with diverse biological activities, including potent hepato-protective and antidepressant-like effects. Fluoxetine (FLX) is one of the most commonly prescribed antidepressant drugs, however; it has recently been postulated to induce liver damage. The present study aimed to assess the benefits of combining half the conventional doses of RSV and FLX in an acute reserpine model of depression. Depression was induced in mice by a single i.p. reserpine injection. Oral administration of FLX (10 mg/kg), RSV (80 mg/kg) or their combination (FLX; $5 \mathrm{mg} / \mathrm{kg}$ and RSV; $40 \mathrm{mg} / \mathrm{kg}$ ) started one hour after reserpine injection and daily for the following two consecutive days. Behavioral tests were performed on the third day. Brain monoamines were assessed. Prevention of neurodegeneration and preservation potential of the DNA integrity were determined according to the brain nitric oxide and 8-hydroxy-2-deoxyguanosine contents. Effect on oxidative stress in both brain and liver was evaluated. Results revealed that combining half the dose of FLX with RSV showed antidepressant activity that was comparable to the effect of using FLX alone and in conclusion; we recommend that further investigations should be conducted to assess the applicability of using combinations of RSV and FLX to treat depression.
\end{abstract}

\section{INTRODUCTION}

Depression is one of the most common neuropsychiatric disorders that affect approximately $20 \%$ of the world population (Schechter, 2005; Thakare and Patel, 2015). It can be caused by one or more changes in the brain, which may or may not be directly related. These changes may include monoamine neurotransmitters depletion, cellular atrophy, neuronal death or decreased neurogenesis (Hurley et al., 2014). Although the mechanism provoking depression has not been clearly elucidated; oxidative stress associated with generation of reactive oxygen species (ROS) has been suggested to play an important role in the pathogenesis of depression. The correlation between ROS overproduction and increased monoamine oxidase (MAO)

* Corresponding Author

Rania F. Ahmed, Department of Pharmacology, National Research

Centre, (ID: 60014618), Dokki, 12622, Giza, Egypt.

Email:dr_rania_fouad@yahoo.com activity has been also proven (Herken et al., 2007). Several studies have suggested that MAOs appear to play important roles in depression. Patients with depression have symptoms that are reflected by changes in brain monoamine neurotransmitters, specifically norepinephrine (NE) and 5-hydroxytryptamine (serotonin, 5-HT). Therefore, it is an important therapeutic strategy for several neuropsychiatric disorders to inhibit MAO and/or increase monoamine neurotransmitters (Bortolato et al., 2008). Unfortunately, the currently available psychiatric drugs are only moderately effective and often associated with significant side effects as well as drug tolerance and resistance. Therefore, it is critical to explore viable new drugs with high efficacy and safety (Ge et al., 2013; Wang et al., 2013). New developments in treatment of depression have become an urgent demand. The undesirable side effects associated with conventional antidepressants encourage scientists to search for new antidepressants of herbal origin. 
In recent years, numerous herbal medicines with antidepressant effects and high safety margins have become a novel pharmacotherapy in the treatment of depression (Ahmed et al., 2014a; Ahmed et al., 2014b; Thachil et al., 2007). Resveratrol (RSV) (3,5,4-trihydroxystilbene) is a polyphenol belonging to the phytoalexin group enriched in the skin of red grapes and other plants specially the Asian herb Polygonum cuspidatum. Researchers have suggested that RSV demonstrates a variety of pharmacological actions including; anti-oxidant, antiinflammatory, anti-cancer and hepato-protective activities and recently was found to have neuro-protective property against excitotoxicity, ischemia and hypoxia (Bai et al., 2010; Liu et al., 2014; Sonmez et al., 2007). The present investigation aimed to assess the effect of combining RSV with the selective serotonin reuptake inhibitor (SSRI); fluoxetine (FLX), which is widely prescribed as a treatment for depression. It has been reported that FLX therapy could be associated with hepatic side effects due to its fluorine content (Beasley et al., 2000; Inkielewicz-Stepniak, 2011). These reports led us to investigate the effect of combining the well-known hepato-protective and potential antidepressant RSV with FLX to alleviate the depressive-like behaviors in mice induced by single intraperitoneal (i.p.) reserpine injection and whether this combination would result in antidepressant effect that is comparable to that of the conventional dose of FLX. In order to achieve our aim, the behavioral, biochemical and neurochemical changes were assessed.

\section{MATERIAL AND METHODS}

\section{Animals}

Animals used were adult male albino mice weighing 20$25 \mathrm{~g}$. purchased from the animal house at the National Research Centre (NRC, Cairo, Egypt). Upon arrival; the animals were acclimatized for 7 days to a quiet colony room, with controlled ambient temperature $\left(22 \pm 1{ }^{\circ} \mathrm{C}\right)$ and a 12 hour natural light/dark cycle, housed eight per cage, fed a standard diet and water was provided ad lib.

The experiments were performed with 8 mice per treatment group according to a randomized schedule. In behavioral tests, animals in every group were intermixed during the observation and the observers were unaware of the treatment conditions. All experiments were performed according to the National Regulations on Animal Welfare and Institutional Animal Ethical Committee (IAEC).

\section{Drugs and drug administration.}

Fluoxetine hydrochloride (Prozac 20mg dispersible tablets, Lilly, Spain), the tablets were freshly suspended in distilled water prior to oral administration. Trans-resveratrol was provided as a generous gift from (Jing Tea LLC), it was provided as Harmoni-T micronized trans-resveratrol capsules for ingestion. The powder in the capsules was freshly dissolved in distilled water just before oral administration. Reserpine was a generous gift from (Novartis Co. Egypt), it was provided as pure powder for injection and it was freshly dissolved in a DMSO/saline mixture (0.1: 10 $\mathrm{ml}$ ) before intraperitoneal injection.

\section{Experimental design}

Depression was induced chemically by administering reserpine ( $8.4 \mathrm{mg} / \mathrm{kg}$, i.p.) (Huang et al., 2004) once on day one of the experiment. Depressed mice were divided into groups ( 8 mice each) and treated as follows: Group (1): receiving distilled water (5ml/kg, p.o.), Group (2): receiving fluoxetine (FLX; $10 \mathrm{mg} / \mathrm{kg}$, p.o.) (Guadarrama-Cruz et al., 2008), Groups (3): receiving resveratrol (RSV; $80 \mathrm{mg} / \mathrm{kg}$, p.o.) (Xu et al., 2010),Group (4): receiving fluoxetine + resveratrol (FLX; $5 \mathrm{mg} / \mathrm{kg}+\mathrm{RSV} ; 40$ $\mathrm{mg} / \mathrm{kg}$, p.o.). All groups received the corresponding drugs one $\mathrm{h}$. after reserpine injection and daily for the following 2 days. A fifth group of 8 mice was used as a universal control group and received DMSO/saline $(5 \mathrm{ml} / \mathrm{kg}$, i.p.) on day one followed by a distilled water ingestion $(5 \mathrm{ml} / \mathrm{kg}$, p.o.) one $\mathrm{h}$. after the reserpine injection and daily for the following two days. On day number 3; one $h$. after the last dose of the drugs, behavioral tests were performed. Twenty-four hours after the last dose of the drugs, the mice were killed by decapitation. Brain and liver tissues were isolated and washed with cold sterile physiological saline, blotted between two damp filter papers and stored at $-80^{\circ} \mathrm{C}$ until use for biochemical analyses.

\section{Behavioral assessment Activity Cage Test}

The general animals' activities were carried out using activity cage device (Columbus Instruments 0170-R1 Auto-Track/ Opto-Varimex-5 System). Each mouse was placed in the cage and its activity was measured as the total animal activity count during $5 \mathrm{~min}$.

\section{Tail Suspension Test}

The TST was performed as described by Steru et al. (1985) (Steru et al., 1985). Each mouse was suspended by its tail from a steel bar using an adhesive tape placed approximately $1 \mathrm{~cm}$ from the tip of the tail, the distance between floor and tail was about $30 \mathrm{~cm}$. The total duration of immobility during a 6-min test was measured.

\section{Forced Swimming Test}

Each mouse was placed for 6 minutes in a cylindrical water tank (40 cm high, $40 \mathrm{~cm}$ diameter) where, water level was about $25 \mathrm{~cm}$ and water temperature was maintained at $23^{\circ} \mathrm{C}$ to $25^{\circ} \mathrm{C}$. The total duration of immobility of each animal in the last 4 minutes was recorded(Porsolt et al., 1977).

\section{Biochemical and neurochemical assessments Determination of brain 8-OHDG}

Isolation and hydrolysis of brain DNA was performed as previously described (Lodovici et al., 1997). The hydrolyzed mixture was centrifuged and the supernatant were injected into the HPLC. The separation of 8-OHDG was performed with an 
LC/Agilent 1200 series HPLC apparatus (USA) using UV detectors. For chromatographic separation we used $\mathrm{C} 18$ reverse phase columns in series (Supelco, 5 pm, I.D. $0.46 \times 25 \mathrm{~cm}$ ); the eluting solution was $\mathrm{H}_{2} \mathrm{O} / \mathrm{CH}_{3} \mathrm{OH}(85: 15 \mathrm{v} / \mathrm{v})$ with $50 \mathrm{mM}$ $\mathrm{KH}_{3} \mathrm{PO}_{4}, \mathrm{pH} 5.5$ at a flow rate of $0.68 \mathrm{ml} / \mathrm{min}$. The UV detector was set at $245 \mathrm{~nm}$. The resulting chromatogram identified the concentration from the sample as compared to that of the standard purchased from Sigma Aldrich.

\section{Determination of brain NO level}

Brain samples were homogenized in $75 \%$ aqueous HPLC grade methanol $(10 \% \mathrm{w} / \mathrm{v})$. Samples were centrifuged at $(4500$ rpm) for 15 minutes, the supernatant was isolated and brain NO level was determined using HPLC according to former method (Papadoyannis et al., 1999). The samples were analyzed on an Agilent HP 1200 series HPLC apparatus (USA). The analytical column was anion exchange PRP-X100 Hamilton, $150 \times 4.1 \mathrm{~mm}$, $10 \mu \mathrm{m}$. The mobile phase was a mixture of $0.1 \mathrm{M} \mathrm{NaCl}$ methanol, at a volume ratio 45:55. The flow rate of $2 \mathrm{ml} / \mathrm{min}$, wavelength adjusted to $230 \mathrm{~nm}$. The resulting chromatogram identified the concentration from the sample as compared to that of the standard purchased from Sigma Aldrich.

\section{Determination of brain monoamines and their metabolites levels}

Each brain tissue was homogenized in $75 \%$ aqueous HPLC grade methanol $(10 \% \mathrm{w} / \mathrm{v})$. The homogenate was spun at 4000 r.p.m. for 15 minutes and the supernatant was isolated. Brain monoamines were detected by HPLC according to method described previously (Pagel et al., 2000).The HPLC system consisted of quaternary pump; a column oven, Rheodine injector and $20 \mu 1$ loop, UV detector. The sample was then injected directly into an AQUA column $15054.6 \mathrm{~mm} 5 \mu \mathrm{C} 18$, purchased from Phenomenex, USA under the following conditions: mobile phase 20mM potassium phosphate, $\mathrm{pH}$ 2.5: methanol (99:1), flow rate $1.5 \mathrm{ml} / \mathrm{min}$, UV $210 \mathrm{~nm}$. The resulting chromatogram identified each monoamine and metabolite position and concentration from the sample as compared to that of the standard purchased from Sigma Aldrich.

\section{Determination of brain and liver MDA and GSH levels}

Tissues were homogenized in ice-cold saline $(20 \% \mathrm{w} / \mathrm{v})$. The homogenate was divided into 2 portions for the determination of MDA(Ruiz-Larrea et al., 1994) and GSH (Bulaj et al., 1998, Ellman, 1959).

\section{Statistical Analysis}

Statistical analysis was carried out by non-parametric K independent samples Kruskal-Wallis test followed by Dunn's multiple comparisons test for the activity cage test and one way ANOVA followed Tukey HSD post hoc multiple comparisons test for the other parameters. Data was expressed as mean \pm SEM. Significances were expressed at $P<0.05$.

\section{RESULTS}

\section{Behavioral tests \\ Activity Cage}

Reserpine injection was associated with a marked decrease in mice activity counts by 6 folds $(23.3 \pm 1.1$ counts vs. $142.9 \pm 10.75$ counts; $P<0.05)$ as compared to the normal control. FLX $(10 \mathrm{mg} / \mathrm{kg})$,or RSV $(80 \mathrm{mg} / \mathrm{kg})$ increased the activity counts by about $32.5 \%$ and $26.6 \%(69.8 \pm 4.05$ and $61.3 \pm 2.68$ counts vs. $23.3 \pm 1.1$ counts; $P<0.05$ ) respectively as compared to the depressed control.(FLX; $5 \mathrm{mg} / \mathrm{kg}$ and RSV; $40 \mathrm{mg} / \mathrm{kg}$ ) markedly increased the activity to $39.3 \%(79.4 \pm 7.26$ counts vs. $23.3 \pm 1.1$ counts; $P<0.05$ ) as compared to the depressed group (Figure 1a).

\section{Tail Suspension Test}

Reserpine injection prominently increased the immobility duration in the TST by 3 folds $(191.4 \pm 8.22 \mathrm{~s}$ vs. $63.00 \pm 3.62 \mathrm{~s} ; P<$ $0.05)$ as compared to the normal control. FLX $(10 \mathrm{mg} / \mathrm{kg})$, RSV $(80 \mathrm{mg} / \mathrm{kg}$ ) or (FLX; $5 \mathrm{mg} / \mathrm{kg}$ and RSV; $40 \mathrm{mg} / \mathrm{kg} ; P<0.05$ ) markedly decreased the immobility duration by about $23 \%, 25 \%$ and $24 \%(146.8 \pm 3.67 \mathrm{~s}, 144.0 \pm 2.24 \mathrm{~s}$ and $145.8 \pm 5.12 \mathrm{~s}$ vs. $191.4 \pm 8.22 \mathrm{~s} ; P<0.05)$ respectively, as compared to the depressed group (Figure 1b).

\section{Forced swimming test}

Reserpine injection significantly increased the immobility duration in the FST by 10 folds $(182.0 \pm 5.59 \mathrm{~s}$ vs. $17.88 \pm 1.65 \mathrm{~s} ; P<0.05)$ as compared to the normal control. FLX $(10 \mathrm{mg} / \mathrm{kg}), \mathrm{RSV}(80 \mathrm{mg} / \mathrm{kg})$ or $(\mathrm{FLX} ; 5 \mathrm{mg} / \mathrm{kg}$ and $\mathrm{RSV}$; $40 \mathrm{mg} / \mathrm{kg} ; \quad P<0.05)$ prominently decreased the immobility duration by about $58 \%, 55 \%$ and $56 \%(76.88 \pm 5.67 \mathrm{~s}, 82.38 \pm 6.11 \mathrm{~s}$ and $80.75 \pm 2.76 \mathrm{~s}$ vs. $182.0 \pm 5.59 \mathrm{~s} ; P<0.05)$ respectively as compared to the depressed group (Figure 1c).

\section{Biochemical and neurochemical assessments. Brain8-hydroxy-2-deoxyguanosine level.}

Reserpine injection elevated the brain 8-OHDG level by about $81 \%(18.56 \pm 0.7 \mathrm{pg} / \mathrm{g}$ vs. $10.2 \pm 0.5 \mathrm{pg} / \mathrm{g} ; P<0.05)$ as compared to the normal control. FLX (10 mg/kg), RSV ( $80 \mathrm{mg} / \mathrm{kg})$ and their combination (FLX; $5 \mathrm{mg} / \mathrm{kg}$ and RSV; 40mg/kg) significantly reduced the brain 8 -OHDG level by about $37,35 \%$ and $41 \%(11.7 \pm 0.7,12.04 \pm 0.8$ and $11.04 \pm 0.9 \mathrm{pg} / \mathrm{g}$ vs. $18.56 \pm$ $0.7 \mathrm{pg} / \mathrm{g}$ respectively; $P<0.05)$ as compared to the depressed group (Figure 2a).

\section{Brain nitric oxide level.}

Reserpine injection increased the brain content of NO by about $60 \%$ as compared to the normal control. FLX $(10 \mathrm{mg} / \mathrm{kg})$, $\mathrm{RSV}(80 \mathrm{mg} / \mathrm{kg}$ ) and their combination (FLX; $5 \mathrm{mg} / \mathrm{kg}$ and RSV; $40 \mathrm{mg} / \mathrm{kg}$ ) significantly decreased the brain NO content by about $29 \%, 32 \%$ and $33 \%(0.94 \pm 0.04,0.91 \pm 0.05$ and $0.89 \pm 0.05$ vs. 1.33 $\pm 0.08 ; P<0.05)$ respectively, as compared to the depressed group (figure $2 b$ ). 


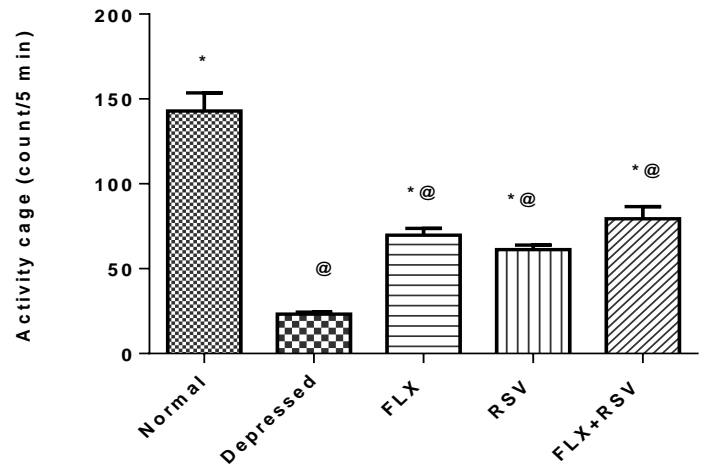

(a)

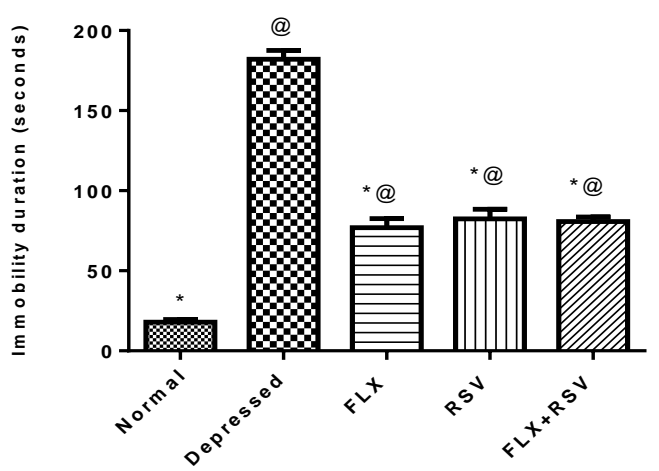

(b)

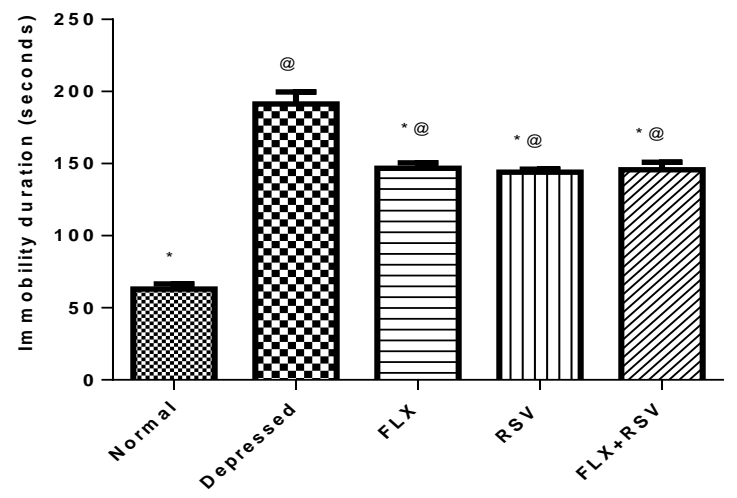

(c)

Fig. 1: Effect of combining fluoxetine with resveratrol on the activity cage count (a), the immobility duration in tail suspension test (b) and forced swimming test (c) in acutely depressed mice. Data was expressed as mean \pm SEM, $n=8$ mice/group, ${ }^{\circledR}$ Significantly different from the normal control, ${ }^{*}$ Significantly different from the depressed group at $\mathrm{P}<0.05$.

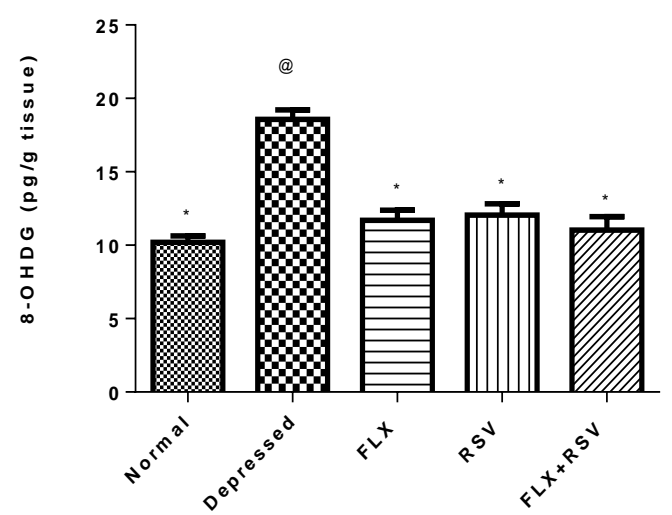

(a)

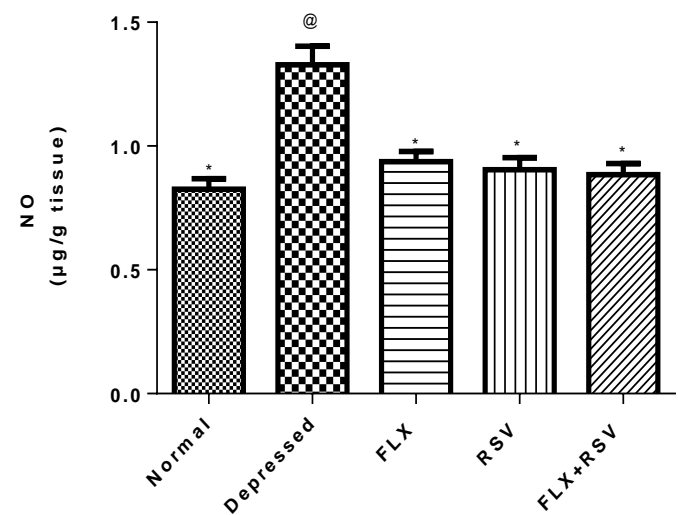

(b)

Fig. 2: Effect of combining fluoxetine with resveratrol on brain levels of 8 -hydroxy-deoxyguanosine (a) and nitric oxide (b) in acutely depressed mice Data was expressed as mean \pm SEM, $\mathrm{n}=8$ mice/group, ${ }^{\circledR}$ Significantly different from the normal control, ${ }^{*}$ Significantly different from the depressed group at $\mathrm{P}<0.05$.

\section{Brain neurotransmitters levels and their metabolites.}

Reserpine injection in mice was associated with a marked decrease in the brain neurotransmitters levels viz. 5-HT, NE and DOP by $23 \%, 28.9 \%$ and $15.6 \%$ respectively. Moreover, induction of acute depression in mice was accompanied by marked increase in the 5-HT and DOP turnover i.e. ratios 5-HIAA/5-HT and DOPAC/DOP. FLX $(10 \mathrm{mg} / \mathrm{kg})$ increased the brain levels of 5-HT, NE and DOP by $21.7 \%, 22.2 \%$ and $20.4 \%$ respectively, decreased 5-HIAA by $32.7 \%$, and decreased the 5-HT and DOP turnover i.e. ratios 5-HIAA/5-HT and DOPAC/DOP by $52 \%$ and $21.7 \%$ respectively, as compared to the depressed group.
RSV $(80 \mathrm{mg} / \mathrm{kg}$ ) showed an elevation in the brain levels of 5-HT, NE and DOP by $17.4 \%, 14.8 \%$ and $18.5 \%$ respectively, a decrease in 5-HIAA by $34.6 \%$ and a decrease in the 5-HT and DOP turnover i.e. ratios 5-HIAA/5-HT and DOPAC/DOP by $45 \%$ and $26 \%$ respectively, as compared to depressed group. (FLX; $5 \mathrm{mg} / \mathrm{kg}$ and RSV; 40mg/kg) increased the brain levels of 5-HT, NE and DOP by $17.4 \%, 25 \%$ and $18 \%$ respectively, decreased 5-HIAA by 56\%and decreased the 5-HT and DOP turnover i.e. ratios 5-HIAA/5-HT and DOPAC/DOP by $62 \%$ and $17 \%$ respectively, as compared to the depressed group (Table 1). 
Table 1: Effect of combining fluoxetine with resveratrolon the brain neurotransmitters levels and their metabolites in acutely depressed mice.

\begin{tabular}{|c|c|c|c|c|c|c|c|c|c|}
\hline \multirow{3}{*}{ GROUPS } & \multicolumn{3}{|c|}{ Neurotransmitter content (ug/g tissue) } & \multicolumn{3}{|c|}{ Metabolite content (ug/g tissue) } & \multicolumn{3}{|c|}{ Ratio of metabolite to its neurotransmitter. } \\
\hline & 5HT & $\mathrm{NE}$ & DOP & 5-HIAA & HVA & DOPAC & 5-HIAA/5HT & HVA/DOP & DOPAC/DOP \\
\hline & Mean \pm SEM & Mean \pm SEM & Mean \pm SEM & Mean \pm SEM & Mean \pm SEM & Mean \pm SEM & & & \\
\hline Normal & $0.3 \pm 0.01^{*}$ & $0.38 \pm 0.01^{*}$ & $0.641 \pm 0.02^{*}$ & $0.23 \pm 0.04^{*}$ & $0.084 \pm 0.004$ & $0.109 \pm 0.003$ & $0.75 \pm 0.12^{*}$ & $0.13 \pm 0.01$ & $0.17 \pm 0.01^{*}$ \\
\hline Depressed & $0.23 \pm 0.004^{\circledR}$ & $0.27 \pm 0.02^{\circledR}$ & $0.544 \pm 0.01^{@}$ & $0.52 \pm 0.01^{\circledR}$ & $0.08 \pm 0.004$ & $0.122 \pm 0.004$ & $2.31 \pm 0.08^{@}$ & $0.15 \pm 0.004$ & $0.23 \pm 0.01^{@}$ \\
\hline FLX & $0.28 \pm 0.01^{*}$ & $0.33 \pm 0.01^{*}$ & $0.653 \pm 0.01^{*}$ & $0.32 \pm 0.02^{*}$ & $0.075 \pm 0.002$ & $0.115 \pm 0.004$ & $1.11 \pm 0.06^{*}$ & $0.12 \pm 0.004$ & $0.18 \pm 0.01^{*}$ \\
\hline RSV & $0.27 \pm 0.01^{*}$ & $0.31 \pm 0.01^{@}$ & $0.645 \pm 0.03^{*}$ & $0.34 \pm 0.03^{* @}$ & $0.072 \pm 0.007$ & $0.108 \pm 0.004$ & $1.27 \pm 0.11^{* @}$ & $0.11 \pm 0.01$ & $0.17 \pm 0.01^{*}$ \\
\hline FLX+RSV & $0.27 \pm 0.01^{*}$ & $0.34 \pm 0.01^{*}$ & $0.645 \pm 0.02^{*}$ & $0.23 \pm 0.03^{*}$ & $0.075 \pm 0.007$ & $0.119 \pm 0.005$ & $0.87 \pm 0.12^{*}$ & $0.12 \pm 0.01$ & $0.19 \pm 0.01$ \\
\hline
\end{tabular}

Data was expressed as mean \pm SEM, $\mathrm{n}=8$ mice/group,

${ }^{\circledR}$ Significantly different from the normal control,

* Significantly different from the depressed group at $\mathrm{P}<0.05$.

Table 2: Effect of combining fluoxetine with resveratrolon the brain and liver levels of glutathione and malondialdehyde in acutely depressed mice.

\begin{tabular}{|c|c|c|c|c|}
\hline \multirow[b]{2}{*}{ Groups } & \multicolumn{2}{|c|}{ Brian antioxidant parameter } & \multicolumn{2}{|c|}{ Liver antioxidant parameter } \\
\hline & $\begin{array}{c}\text { GSH } \\
(\mu \mathrm{mol} / \mathrm{g} \text { tissue })\end{array}$ & $\begin{array}{c}\text { MDA } \\
\text { (nmol/g tissue) }\end{array}$ & $\begin{array}{c}\text { GSH } \\
(\mu \mathrm{mol} / \mathrm{g} \text { tissue })\end{array}$ & $\begin{array}{c}\text { MDA } \\
\text { (nmol/g tissue) }\end{array}$ \\
\hline Normal & $1.51 \pm 0.06$ & $34.19 \pm 1.43^{*}$ & $15.45 \pm 0.57^{*}$ & $23.29 \pm 1.61$ \\
\hline Depressed & $1.33 \pm 0.03$ & $59.05 \pm 0.28 @$ & $9.29 \pm 0.85^{@}$ & $37.99 \pm 1.6^{@}$ \\
\hline FLX & $1.44 \pm 0.05$ & $40.12 \pm 1.1^{* @}$ & $20.03 \pm 0.76^{* @}$ & $30.36 \pm 0.75^{* @}$ \\
\hline RSV & $1.43 \pm 0.06$ & $39.19 \pm 0.17 *$ & $20.50 \pm 0.57 * @$ & $27.79 \pm 1.46^{*}$ \\
\hline FLX+RSV & $1.46 \pm 0.05$ & $39.21 \pm 0.61 *$ *@ & $20.22 \pm 1.01^{* @}$ & $29.29 \pm 1.81^{*}$ \\
\hline
\end{tabular}

Data was expressed as mean \pm SEM, $\mathrm{n}=8$ mice/group,

${ }^{\circledR}$ Significantly different from the normal control,

*Significantly different from the depressed group at $\mathrm{P}<0.05$.

\section{Brain and liver oxidative stress biomarkers}

Reserpine injection in mice was associated with a significant increase in the brain and liver content of MDA by about $73 \%$ and $63 \%$ respectively, as compared to the normal controlalong with a significant decrease in the liver GSH level by $30 \%$ with no change in the brain GSH content. FLX $(10 \mathrm{mg} / \mathrm{kg})$, RSV $(80 \mathrm{mg} / \mathrm{kg}$ ) and their combination (FLX; $5 \mathrm{mg} / \mathrm{kg}$ and RSV; $40 \mathrm{mg} / \mathrm{kg}$ ) resulted in a marked decrease in the brain MDA content by about $32 \%, 34 \%$ and $34 \%$ respectively, in addition to a significant decrease in the liver MDA content by 20\%, 27\% and $23 \%$ respectively as compared to the depressed control. Moreover; liver GSH levels were increased by about 30\%, 33\% and 31\% compared to the normal control (Table 2).

\section{DISCUSSION}

Reserpine is a monoamine depletor that blocks the vesicular monoamine transporter for neuronal transmission or storage, thus promoting oxidative catabolism by $\mathrm{MAO}$ (Lohr et al., 2003); this makes its injection a reliable model of depression in rodents(Oe et al., 2010). Results of the present study revealed that acute reserpine injection resulted in depressive-like behaviors such as decrease in the mice activity in the activity cage, increased immobility durations in both the TST and FST along with other physiological changes represented by prolonged monoamines depletion and oxidative stress. Foregoing investigations indicated that such physiological changes can persist for more than one week and thus the effectiveness of antidepressants could be assigned by their capability to reverse the depressive-like effects of reserpine (Arora and Chopra, 2013; Huang et al., 2004).

The central nervous system is highly vulnerable to damage from oxidative stress; 8-hydroxylated guanine species such as 8-oxoguanine and 8-OHDG are repair products of oxidized guanine lesions. 8-OHDG content is considered a sensitive biomarker of the oxidative DNA damage and repair(Kouda et al., 2001); there are several hundred reports linking increased concentrations of 8-OHDG to increased oxidative stress or disease states(Arnett et al., 2005). Nitric oxide (NO) is another important and versatile molecule in neurogenesis and accumulating evidence supports the hypothesis that it plays a critical role in neurodegenerative disorders(Bogdan, 2001). Activation of the inducible form of NO synthase (iNOS) and NO production take place during many neuropathological conditions. iNOS is responsible for the cytotoxic action of macrophages and neutrophils and the increase in NO has been implicated in neurodegeneration. NO has also been found to participate in Fas-mediated apoptosis in Jurkat cells and NO donor can induce apoptosis of murine thymocytes. Implication of this molecule in cellular toxicity has been suggested by the use of NO synthase inhibitors or knockout mice in different models of demyelinating and neurodegenerative diseases conditions(Blais and Rivest, 2004). The present study elucidated that acute reserpine injection in mice was associated with an elevation in the brain 8-OHDG and NO levels, as compared to the normal control.

Studies of the neurobiological mechanism suggested the involvement of neurotransmitter systems in depression, exhibiting abnormalities in the brain levels of 5-HT, NE, DOP and their metabolites viz. 5-HIAA, HVA and DOPAC(Vines et al., 2012, Yu et al., 2013). The decreased brain content of 5-HT has been theorized to be a core pathogenic factor in depression (Svenningsson et al., 2006). Consistent with previous studies, results of our study showed that acutely depressed mice are associated with a decrease in 5-HT and increase in its metabolite; 5-HIAA, which reflect increased metabolism of 5-HT. Increased 
level of brain 5-HT turnover i.e. 5-HIAA/5-HT ratio has been also observed. Moreover, acutely depressed mice were accompanied with a decrease in the brain DOP content with an increase in its metabolite DOPAC indicating DOP turnover i.e. increase in the ratio DOPAC/DOP.

It has been postulated that FLX has adverse effects on the liver in both patients and animal models. These include disrupted liver functions and oxidative stress and hepatocellular changes(Beasley et al., 2000, Inkielewicz-Stepniak, 2011). Resveratrol; which is well known for its hepato-protective effect(Fan et al., 2009, Farghali et al., 2009, Zhang et al., 2013); was previously investigated in our laboratory and showed an antidepressant activity in both acute and chronic models and the results were comparable to those of FLX. Moreover; it showed better hepato-protective action after chronic administration presented by lower ALT and AST levels(Ahmed et al., 2014a, Ahmed et al., 2014b).

These studies led us to investigate the advantageous effects of combining FLX and RSV on the oxidative stress induced in the brain and the liver as well as the potential neuro-protective property and the antidepressant activity of the combination in an acute reserpine model of depression. In the present investigation, combining FLX (5 mg/kg) and RSV (40mg/kg) increased the score of movement in the activity cage and decreased the immobility duration in both the TST and the FST. Brain NO and 8-OHDG contents were retrieved to normal value. Liver GSH level was markedly elevated and brain and liver levels of MDA were reduced. This observation is consistent with previous reports which demonstrated that RSV has potential effects on controlling free radical production (Franco et al., 2013). In Addition, the potential antidepressant effect of RSV was also detected by former researchers who reported that this effect might be attributed to the antioxidant activity and involves the hypothalamic-pituitaryadrenal axis, serotonergic, noradrenergic and dopaminergic systems (Hurley et al., 2014, Wang et al., 2013).

Previous studies have shown that 5-HT turnover decreased in the hippocampus, frontal cortex and striatum after RSV treatment (Yu et al., 2013). Treatment of acutely depressed mice with RSV alone showed an increase in the brain contents of 5-HT and DOP and their turnover with a decrease in the metabolite 5-HIAA. Treatment with the combination (FLX; 5 $\mathrm{mg} / \mathrm{kg}$ and RSV; $40 \mathrm{mg} / \mathrm{kg}$ ) showed an increase in the brain contents of 5-HT, NE and DOP. The increased brain NE content is probably due to the potentiation of the conversion of DOP to NE. Moreover, combining RSV with FLX markedly decreased the brain content of the metabolite 5-HIAA and the ratio 5-HIAA/5HT suggesting a 5-HT reuptake inhibitor activity and/or MAO inhibitor activity. It worth mentioning that the results of FLX and the combination were non-significantly different regarding the 5HT level. Moreover; combination lowered the 5-HIAA level. From all these findings, it can be concluded that combining RSV with FLX had beneficial effects in the treatment of acutely depressed mice via prevention of oxidative DNA fragmentation, neurodegeneration, monoamines degradation as well as brain and liver oxidative stress. The overall results of the combination were better than that obtained using the conventional dose of FLX alone.

\section{REFERENCES}

Ahmed RF, Abdel-Rahman RF, Abdallah H, Saleh D, Farid O, Hessin A, . Antidepressant-like effect of resveratrol in a subchronic model of depression. J Arab Soc Med Res, 2014a; 9: 48-53.

Ahmed RF, Abdel-Rahman RF, Farid O, El-Marasy S, Hessin A. Combined hepatoprotective and antidepressant effects of resveratrol in an acute model of depression. Bull Fac Pharm Cairo Univ, 2014b; 52: 191-97.

Arnett SD, Osbourn DM, Moore KD, Vandaveer SS, Lunte CE. Determination of 8-oxoguanine and 8-hydroxy-2'-deoxyguanosine in the rat cerebral cortex using microdialysis sampling and capillary electrophoresis with electrochemical detection. J Chromatogr B Analyt Technol Biomed Life Sci, 2005; 827: 16-25.

Arora V, Chopra K. Possible involvement of oxido-nitrosative stress induced neuro-inflammatory cascade and monoaminergic pathway: underpinning the correlation between nociceptive and depressive behaviour in a rodent model. J Affect Disord, 2013; 151: 1041-52.

Bai Y, Mao QQ, Qin J, Zheng XY, Wang YB, Yang K, Shen HF, Xie LP. Resveratrol induces apoptosis and cell cycle arrest of human T24 bladder cancer cells in vitro and inhibits tumor growth in vivo. Cancer Sci, 2010; 101: 488-93.

Beasley CM, Jr., Nilsson ME, Koke SC, Gonzales JS. Efficacy, adverse events, and treatment discontinuations in fluoxetine clinical studies of major depression: a meta-analysis of the $20-\mathrm{mg} /$ day dose. J Clin Psychiatry, 2000; 61: 722-8.

Blais V, Rivest S. Effects of TNF-alpha and IFN-gamma on nitric oxide-induced neurotoxicity in the mouse brain. J Immunol, 2004; 172: 7043-52.

Bogdan C. Nitric oxide and the immune response. Nat Immunol, 2001; 2: 907-16.

Bortolato M, Chen K, Shih JC. Monoamine oxidase inactivation: from pathophysiology to therapeutics. Adv Drug Deliv Rev, 2008; 60: 1527-33.

Bulaj G, Kortemme T, Goldenberg DP. Ionization-reactivity relationships for cysteine thiols in polypeptides. Biochemistry, 1998; 37: 8965-72. 1959; 82: 70-7.

Ellman GL. Tissue sulfhydryl groups. Arch Biochem Biophys,

Fan G, Tang JJ, Bhadauria M, Nirala SK, Dai F, Zhou B, Li Y, Liu ZL. Resveratrol ameliorates carbon tetrachloride-induced acute liver injury in mice. Environ Toxicol Pharmacol, 2009; 28: 350-6.

Farghali H, Cerny D, Kamenikova L, Martinek J, Horinek A, Kmonickova E, Zidek Z. Resveratrol attenuates lipopolysaccharideinduced hepatitis in D-galactosamine sensitized rats: role of nitric oxide synthase 2 and heme oxygenase-1. Nitric Oxide, 2009; 21: 216-25.

Franco JG, Lisboa PC, Lima NS, Amaral TA, Peixoto-Silva N, Resende AC, Oliveira E, Passos MC, Moura EG. Resveratrol attenuates oxidative stress and prevents steatosis and hypertension in obese rats programmed by early weaning. J Nutr Biochem, 2013; 24: 960 6.

Ge JF, Peng L, Cheng JQ, Pan CX, Tang J, Chen FH, Li J. Antidepressant-like effect of resveratrol: involvement of antioxidant effect and peripheral regulation on HPA axis. Pharmacol Biochem Behav, 2013; 114-115: 64-9.

Guadarrama-Cruz G, Alarcon-Aguilar FJ, Lezama-Velasco R, Vazquez-Palacios G, Bonilla-Jaime H. Antidepressant-like effects of Tagetes lucida Cav. in the forced swimming test. J Ethnopharmacol, 2008; 120: $277-81$

Herken H, Gurel A, Selek S, Armutcu F, Ozen ME, Bulut M, Kap O, Yumru M, Savas HA, Akyol O. Adenosine deaminase, nitric oxide, superoxide dismutase, and xanthine oxidase in patients with major depression: impact of antidepressant treatment. Arch Med Res, 2007; 38: 247-52. 
Huang QJ, Jiang H, Hao XL, Minor TR. Brain IL-1 beta was involved in reserpine-induced behavioral depression in rats. . Acta Pharmacol Sin, 2004; 25: 293-96.

Hurley LL, Akinfiresoye L, Kalejaiye O, Tizabi Y. Antidepressant effects of resveratrol in an animal model of depression. Behav Brain Res, 2014; 268: 1-7.

Inkielewicz-Stepniak I. Impact of fluoxetine on liver damage in rats. Pharmacol Rep, 2011; 63: 441-7.

Kouda K, Nakamura H, Fan W, Horiuchi K, Takeuchi H. The relationship of oxidative DNA damage marker 8-hydroxydeoxyguanosine and glycoxidative damage marker pentosidine. Clin Biochem, 2001; 34: 247-50.

Liu D, Zhang Q, Gu J, Wang X, Xie K, Xian X, Wang J, Jiang $\mathrm{H}$, Wang Z. Resveratrol prevents impaired cognition induced by chronic unpredictable mild stress in rats. Prog Neuropsychopharmacol Biol Psychiatry, 2014; 49: 21-9.

Lodovici M, Casalini C, Briani C, Dolara P. Oxidative liver DNA damage in rats treated with pesticide mixtures. Toxicology, 1997; 117: 55-60.

Lohr JB, Kuczenski R, Niculescu AB. Oxidative mechanisms and tardive dyskinesia. CNS Drugs, 2003; 17: 47-62.

Oe T, Tsukamoto M, Nagakura Y. Reserpine causes biphasic nociceptive sensitivity alteration in conjunction with brain biogenic amine tones in rats. Neuroscience, 2010; 169: 1860-71.

Pagel P, Blome J, Wolf HU. High-performance liquid chromatographic separation and measurement of various biogenic compounds possibly involved in the pathomechanism of Parkinson's disease. J Chromatogr B Biomed Sci Appl, 2000; 746: 297-304.

Papadoyannis L, Samanidou V, Nitsos C. Simultaneous determination of nitrite and nitrate in drinking water and human serum by high performance anion-exchange chromatography and UV detection. Journal of Liquid Chromatography and Related Technologies, 1999; 22: 2023-41.

Porsolt RD, Bertin A, Jalfre M. Behavioral despair in mice: a primary screening test for antidepressants. Arch Int Pharmacodyn Ther, 1977; 229: 327-36.

Ruiz-Larrea MB, Leal AM, Liza M, Lacort M, De Groot $\mathrm{H}$. Antioxidant effects of estradiol and 2-hydroxyestradiol on iron-induced lipid peroxidation of rat liver microsomes. Steroids, 1994; 59: 383-88.

Schechter LE. Major depressive disorder. Curr Pharm Des, 2005; 11: 143-4.

Sonmez U, Sonmez A, Erbil G, Tekmen I, Baykara B. Neuroprotective effects of resveratrol against traumatic brain injury in immature rats. Neurosci Lett, 2007; 420: 133-7.
Steru L, Chermat R, Thierry B, Simon P. The tail suspension test: a new method for screening antidepressants in mice. Psychopharmacology (Berl), 1985; 85: 367-70.

Svenningsson P, Chergui K, Rachleff I, Flajolet M, Zhang X, El Yacoubi M, Vaugeois JM, Nomikos GG, Greengard P. Alterations in 5HT1B receptor function by 11 in depression-like states. Science, 2006; 311: 77-80.

Thachil AF, Mohan R, Bhugra D. The evidence base of complementary and alternative therapies in depression. J Affect Disord, 2007; 97: 23-35.

Thakare VN, Patel BM. Potential targets for the development of novel antidepressants: future perspectives. CNS Neurol Disord Drug Targets, 2015; 14: 270-81

Vines A, Delattre AM, Lima MM, Rodrigues LS, Suchecki D, Machado RB, Tufik S, Pereira SI, Zanata SM, Ferraz AC. The role of 5HT(1)A receptors in fish oil-mediated increased BDNF expression in the rat hippocampus and cortex: a possible antidepressant mechanism. Neuropharmacology, 2012; 62: 184-91.

Wang Z, Gu J, Wang X, Xie K, Luan Q, Wan N, Zhang Q, Jiang H, Liu D. Antidepressant-like activity of resveratrol treatment in the forced swim test and tail suspension test in mice: the HPA axis, BDNF expression and phosphorylation of ERK. Pharmacol Biochem Behav, 2013; 112: 104-10.

Xu Y, Wang Z, You W, Zhang X, Li S, Barish PA, Vernon MM, Du X, Li G, Pan J, Ogle WO. Antidepressant-like effect of transresveratrol: Involvement of serotonin and noradrenaline system. Eur Neuropsychopharmacol, 2010; 20: 405-13.

Yu Y, Wang R, Chen C, Du X, Ruan L, Sun J, Li J, Zhang L, O'Donnell JM, Pan J, Xu Y. Antidepressant-like effect of trans-resveratrol in chronic stress model: behavioral and neurochemical evidences. J Psychiatr Res, 2013; 47: 315-22.

Zhang A, Sun H, Wang X. Recent advances in natural products from plants for treatment of liver diseases. Eur J Med Chem, 2013; 63: 570-7.

\section{How to cite this article:}

Ahmed-Farid OAH, Ahmed RF, Saleh DO. Combination of resveratrol and fluoxetine in an acute model of depression in mice: Prevention of oxidative DNA fragmentation and monoamines degradation. J App Pharm Sci, 2016; 6 (06): 001-007. 